of "dry eyes," but is attended by structural changes leading to blindness. As regards "dry mouth," we have, as I have all along insisted, nothing more than absence of salivary and buccal secretion. No secondary changes appear to follow, however long this arrest of secretion may continue. It is probable also that there are various degrees of it, and that many cases are incomplete. Thus I an afraid that the term "xerostomia" may, to those who hear it for the first time, suggest much more than is really meant; whereas the term "aptyalism," although it might have hurt the feelings of a few scholars, would have deceived no one. It may be well, however, now to let the matter rest, and to abandon the latter word; but I cannot conclude without expressing a hope that the original, although somewhat homely, expression "dry mouth" will keep its place as the name for the disease in English medical literature.

Feb. 1889 . I am, Sirs, yours faithfully,

JONATHAN HUTCHINSON.

To the Editors of THE LANCET.

SIRS,-The interesting letter of Dr. Hadden in your issue of the 9th inst. deals with a subject which has long been in need of some authoritative expression of opinion on the part of our profession, and it is to be hoped that the cautions procedure of Mr. Jonathan Hutchinson in the case of the compound "xerostomia" will henceforth serve as an example to those who are about to frame some new term of scientific nomenclature. I remember a paper being brought forward a few years ago, at one of our Societies, on a subject which the author was pleased to call "anhydrotics," meaning thereby a class of substances like atropine, capable of diminishing or restraining cutaneous secretion. Of course, the correct form of the term, if adopted at all, would be "anidrotics"; and, though the error was pointed out at the time, the paper subsequently appeared in a monthly medical periodical, with the ridiculous heading of "an $h$ i. drotics." But I adduce this only as an instance of the reprehensible indifference which has hitherto prevailed as to the proper canons of construction to be followed in such cases. More pertinent to the subject of Dr. Hadden's letter is the well-known "parthenogenesis"-a form which is barbarous to the last degree, and ought to have been "parthenogenesia." The orthography of xerostomia is wholly in conformity with the laws of Greek formation, and I hope its pronunciation may also come to be in accordance with the rules of modern Greek, which place the accent in such words on the penultimate vowel, $i$, so that it would be sounded "xerostoméea."

I remain, Sirs, yours faithfully,

Sussex Gardens, Hyde Park, Feb. 10th.

T. Fitz-PATRICK.

\section{THE PROTECTION OF THE MEDICAL PROFESSION.}

\section{To the Editors of THE LANCET.}

Sirs,-Thorough discussion of the subject broached in your leading article of to-day ought to lead to practical results. No one who has observed the procedures of Parliament during the debates upon projects of medical legis lation brought forward by private members and ministers within late years can have failed to recognise the ideas which statesmen have firmly adopted in conferring by statute privileges and powers upon the profession. One of the principles uniformly acted upon by the Legislature has been that no privilege should be conferred which might be merely to the advantage of the profession whilst not demonstrably to the benefit of the public. At first view it might be reasonably thought that statesmen would be ready to forbid absolutely to those not possessing a legal qualification the pursuit of any branch of practice for gain; but no such arbitrary restriction has ever been seriously entertained by the Legislature. A sweeping enactment, which should entirely forbid practice by the unqualified, would not only be an interference with their libertyjustifiable no doubt,--but it would also be an interference with the liberty of the public, who, strange as it may seem, often prefer knowingly an unqualified to a qualified practitioner. This feeling is not confined to the ignorant, but has its representatives among all classes; and not so long ago we have seen a noble lord-who, far from being a fool, is a man of culture and uncommon literary power-de- liberately and elaborately setting forth, among other arguments and statements of a like purport, his belief in the superiority of quack bone-setters over the best surgeons of the day. The medical herbalist, the medical electrician, and the whole tribe of sham medical practitioners to which they belong have their votaries and friends; and no Government would think of forcing upon the country a paternal measure virtually forbidding recourse to these irregular practitioners by those of the public who choose or prefer them. What the Legislature has shown itself thoroughly willing to do is to prevent irregular practitioners from palming themselves off as qualified men by the use of sham medical titles. The present medical law is defective and sadly needs amendment in this particular; and there cannot be the least doubt that so soon as the profession with anything like unanimity shall demand reform it will be speedily effected. This is proved by what has happened in the case of the dental profession. Surely if the Legislature has shown itself willing to prevent unqualified practitioners from styling themselves dentists, it will be not less ready to put a stop to the assumption of false medical titles by fraudulent doctors. At present there exists the. anomaly that an unqualified quack, who dare not call himself "dentist," may with impunity assume the title of "doctor." The quack dentist of the day has not been slow to perceive this, and he now seeks to evade the law by keeping a "dental establishment," and styling himself "doctor," on the strength of possessing an American diploma in dental surgery. Many columns of THE LANCET would be needed for discussion of the numerous points referred to in your article. I have at least indicated one direction in which the profession might find relief from injury of a serious kind. There are many other directions. in which an equal amount of good might be certainly accomplished if the profession would only combine and act. together. I remain, Sirs, your obedient servant,

Wimpole-street, Feb. 9th, 1839.

HENRY SEWILL.

\section{To the Editors of THE LANCET.}

SIRs,-Consideration for your valuable space has prevented me from again writing to you on this sulject. I am glad to see by the various letters that some interest is taken in the question, though $\mathrm{I}$ think we are proceeding. rather slowly. I have not time to notice all your correspondents, but I would ask space to notice one in particular-viz., "A Doctor of Medicine,"-as, if his views with reard to action were a reflection of the opinions of the profession generally, my scheme would be at once both hopeless and useless. I have read and re-read his letter carefully, but the more I do so the more I fail to see the relevancy of his remarks. First, he asks whether it would be possible to induce independent members to submit to the control of any association. Now, if he will take the trouble to read iny letter again, he will find in it that nowhere do I claim the right to dictate what another man is to do. It would be simply impossible to control every member of our profession; but, while acknowledging this, surely it is not unreasonable to bring a fair amount of pressure to bear on flexible brethren? My contention has always been that men who do what we may call irregular actions are often as much sinned against as sinning, and are often forced by the present unfair competition into action which they must know is at once unjust and ruinous to themselves as well as their professional brethren. A little help, a little of "the animating spirit of a collective body," will, I trust, work wonders in recalling these erring members by giving them a chance to respect themselves and their profescion. Again, does your correspondent seriously mean the profession to believe that the Medical Council will take action for the protection of the profession? Some action we may fairly call upon them to take-such as the putting down of irregular practice, and the insistence of compulsory registration. Barristers have their societies, and solicitors their Incorporated Law Society, to protect them. Why, therefore, should our Council not protect us? they at least cannot plead want of funds (and funds, moreover, supplied by the profession). If an outsider to the charmed law circle vaguely writes a letter to imply that he is a solicitor, what is the result? Why, immedjate and successful action, and the luckless would-be solicitor soon gets taught a lesson, and finds himself mulcted in serious penalties. Surely, therefore, if it is just to protect a 
solicitor, why not also a doctor? Registration, I also say, should be compulsory; but will mere registration put down dishonourable practice from shady registered and qualified men? Never. Our only hope is, as I have before said, to act on their better feelings, and try to get them to respect themselves and their profession. I feel sure that upon consideration your correspondent will agree with me that it would be utterly hopeless to expect the Council to help us in doing things which we are clearly bound to do for ourselves. The question is, will an association such as is proposed help us or not? I say decidedly it will, if we can by -association present ourselves a solid phalanx-I was almost going to say to the enemy-and stand shoulder to shoulder. Can it be doubted that we shall in time be able to check the canker in our midst, and once again restore ourselves to the position we once held? I totally repudiate all notion of trades unionism. I simply ask for the profession a fair equivalent for our work done to the public, and to put an end to the miserable Dutch-auction business that has arisen in our midst during the last fifteen years; and, in doing so, I am confident that if $I$ am successful $I$ shall be doing as much benefit to the general public as to my own profession. Finally, I ask, is action to be taken or not? I am ready to help, and to guide, if action is to be taken. I can admire your correspondent's patience, if $\mathrm{I}$ do not intend to practise $\mathrm{it}$. Patience is the panacea for delay, he says. Very true; but it is weary waiting. We all, as school-boys, have read of the patient rustic, who, arriving at the unfordable stream, sat down " patiently" to wait till it had flowed by. Perhaps he still waits. And, as there are exceptions to every rule, and streams in the Fast do dry up sometimes, in time, may be, when the Council is got to take action, we all, with the happy rustic, shall pass over to the "promised land," and find compensation for our weary waiting. But when? I am afraid echo will sadly answer, When?

I am, Sirs, your obedient servant,

Feb. 4th, 1889

P.S. - I cannot reply to all your correspondents, but I should be very glad if as many as possible will put themselves in communication with me.

** We have received so many letters on the above subject that we find it impossible to find space for even a tithe of them. The question is one which evidently excites widespread interest; but the correspondence elicited thus far does not serve clearly to elucidate the best means of securing a remedy for the evils complained of. $-\mathrm{ED}$. L.

\section{RTGORS.}

To the Editors of THE LANCET.

Surs,-I have read Mr. Gilchrist Burnie's article on "Rigors: what they may indicate," in your issue for Jan. 26th, with much interest. In a paper published by me in 1881, entitled "Observations on Puerperal Temperatures," I wrote as follows: "A rigor is not simply an indication of the advent of the febrile condition; it demonstrates that perverted function has already taken internal possession; it is the signal of distress which the nervous system throws out on its being perturbed by the invading malady. That rigors are not always present, or, if so, unnoticed, is not singular. But it is, as usual, an experience to find, as naturally to be expected, that metric affections accompanied with much pain are signalised by a decided rigor. The recurrent rigors characteristic of pyæmic affections are to be regarded as indicating the attempts of the system to throw off the repeated doses of the poison by crises. The rigors which are not uncommonly an accompaniment of cases which are of purely mental causation are accounted for in the same way; they are manifestations of internal nervo's irritation. In slowly invaded cases, where the disease is more gradual and insidious in development, the climax as shown by rigor is seldom reached. Possibly the nervous sensibilities are too much exhausted to resist the intruding evil after it has assumed such dimensions as to be of vital concern. In such cases the vitality has been previously undermined. In some terribly rapid cases of puerperal death there is no time for the exhibition of rigor; the system succumbs to the poison ere it has had time to

I Transactions of the Edinburgh Obstetrical Society, vol. vi. summon resistance. In many cases the rigor is so mild that it escapes notice, and in others $I$ believe it is never present owing to individual peculiarity or to some of the preceding causes." The foregoing had special reference to the puerperal condition, but is pretty widely applicable. I am glad to find additional corrobation of my interpretation of rigors in Mr. Burnie's valuable clinical contribution.

I am, Sirs, yours truly,

A. D. Leith NAPIER, M.D.

Beaufort-gardens, S.W., Jan. 30th, 1889.

\section{I D I F E R F O R E PS. To the Editors of THE LANCET.}

SIRS,-In Dr. Haslam's letter in The LANCET of the 9 th inst. concerning my forceps there are some remarks which are most misleading, and which call for an immediate reply from me.

Speaking of the handle of the upper blade, he says: "If flexed forwards (as in Mr. Blenliarne's) the thigh and calves of the patient would utterly prevent introdnction." (!) Dr. Haslam must imagine the patient to be lying in a very peculiar position to have arrived at this remarkable conclusion, and his opinion is simuply theoretical; whereas I have proved on several occasions by practical experience the extreme utility of my invention. Had I not done so, I should scarcely have taken the trouble to introduce my forceps to the notice of the profession. Then again, although this is a very "knowing" age, it is certainly news to me that a uterus can diagnose as to whether it is an upper or a lower blade that is introduced first, and repel the intrusion of a lower blade more than that of an upper one, the fact being that very often even a finger being introduced into the uterus will set up contraction of that organ. Lastly, in the "P.S." to Dr. Haslam's letter, he says: "The wood. cut is an inaccurate representation of $\mathrm{my}$ forceps." This is impossible and contrary to fact, as, to ensure there being no mistake, I had the upper blade of Dr. Haslam's forceps photographed, and it was from that photograph (of which I sent copies to yourselves) that Messrs. Coxeter and Son, the makers of Dr. Haslam's forceps as well as of my own, had the engraving taken. I will not trespass on your valuable space to enter into any minor matters, but remain Yours faithfully,

Leicester, Feb. 9th, 1839. W. L'Heureux Blenkarne.

\section{CERTIFYING FACTORY SURGEONS. To the Editors of THE LANCET.}

SIRs, - I think it is quite time, seeing that employers of labour have had an interview with the Home Secretary, for the certifying surgeons to meet to consider their position, and, if thought desirable, to present their opinions to the Home Secretary. I submit that there is as much need now as there ever was for the office of the certifying surgeon for many reasons, which are obvious perhaps not so much for the purpose of filling up a certificate of age as for determining the fitness for work \&c. I hope the surgeons holding these appointments will combine themselves into $a$ society forthwith to discuss the whole bearings of the subject. I am, Sirs, yours truly, Accrington. Feb. 12th, $1889 . \quad$ RICHARD ClaytoN.

\section{NORTHERN COUNTIES NOTES.} (FROM OUR OWN CORRESPONDENT.)

\section{Newcastle Royal Infirmary.}

THE annual meeting of the Royal Infirmary has been held, and the report, on the whole, must be considered satisfactory. It is impossible in this place to refer to more than a few points of interest. The whole number of in. patients received into the Infirmary during the year has been 3175 , being 175 more than were received during the year 1887. The average cost of each patient has been £3 $12 s .2 \frac{1}{2} d$.; last year it was $£ 312 s .7 d$. Not long ago the cost for several years was above $£ 5$ a patient; in 1887 it

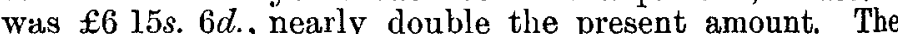
number of deaths has been 194, giving a death-rate of $6 \cdot 11$; 